\title{
User evaluation of three wheelchair securement systems in large accessible transit vehicles
}

\author{
Linda van Roosmalen, PhD; ${ }^{*}$ Patricia Karg, MS; Douglas Hobson, PhD; Michael Turkovich, MS; Erik Porach, BS \\ Department of Rehabilitation Science and Technology, Rehabilitation Engineering Research Center on Wheelchair \\ Transportation Safety, University of Pittsburgh, Pittsburgh, PA
}

\begin{abstract}
Ease of use, comfort, security, and independent use of three types of wheelchair securement systems were evaluated in a large accessible transit vehicle by 20 wheelchair and scooter users. The securement systems included a 4-point tie-down system, a prototype autodocking system, and a prototype rear-facing wheelchair passenger (RF-WP) system. Study participants took a 15-minute city ride and completed a survey. Participants responded positively to the autodocking and RF-WP systems that were quicker and easier to use and allowed more independent use than the 4-point tie-down system $(p<0.001)$. There was concern regarding the RF-WP system that rear-facing travel made it more difficult to see upcoming stops and was less comfortable than a forward-facing ride and that the system may damage wheelchair wheels during use. The majority of participants preferred using an autodocking system because it allowed secure and independent forward-facing travel. Participants found it undesirable, however, that a wheelchair-mounted docking adaptor was needed to use the autodocking system. Study results indicate a need for improved securement systems for forward-facing use that do not require a wheelchair adaptation and can be easily and independently used by wheelchair and scooter users.
\end{abstract}

Key words: autodocking, independent use, passenger injury, public transportation, rear facing, tie-down, transit, usability, wheelchair securement, wheelchair transportation.

\section{INTRODUCTION}

Large accessible transit vehicles (LATVs) commonly have 4-point tie-down systems installed that comply with Federal regulations implementing the Americans with Disabilities Act (ADA) [1]. When properly used, these systems can prevent excessive movement and tipping of common wheeled mobility devices. Even though LATVs are required to have wheelchair securement systems installed, studies have revealed that these systems often go unused [2-3]. Reasons for lack of wheelchair securement use include systems that are difficult to use [3], lack of proper driver training [4-5], lack of compatibility between wheelchairs and the systems [4], and systems that do not allow independent use [3-4].

\footnotetext{
Abbreviations: $\mathrm{ADA}=$ Americans with Disabilities Act, ANOVA = analysis of variance, $\mathrm{FEB}=$ forward excursion barrier, ISO = International Organization for Standardization, LATV = large accessible transit vehicle, RESNA WC19 = Rehabilitation Engineering and Assistive Technology Society of North America Wheelchair Standard 19, RF-WP = rear-facing wheelchair passenger, UDIG = universal design interface geometry.

*Address all corr espondence to Linda van Roosmalen, PhD; LINC Design LLC, 139 Shannon Heights Dr, Verona, PA 15147; 412-401-8194. Email: info@lincdesign.biz DOI:10.1682/JRRD.2010.07.0126
} 
A major barrier to the development of independentuse wheelchair securement systems that are compatible with the operational needs of LATVs is that voluntary standards developed for wheelchair securement systems focus on design and testing for use in private vehicles [6]. This requires securement systems to withstand high forces experienced in high-impact motor vehicle collisions, and as a result, the standards have stringent performance requirements [7-8]. While these standards are necessary and have been effective in improving the safety of wheelchair securement systems for use in private vehicles where severe crashes are likely to occur, the LATV environment is relatively safe, as passengers in this environment are rarely exposed to the high accelerations experienced by passengers in smaller vehicles [9-10]. Research estimates that passengers will experience a crash of $5 \mathrm{G}$ or greater crash once in every 27 million miles traveled and $10 \mathrm{G}$ or greater once in every 455 million miles when traveling by LATV $[4,11]$.

Even though the risk of a severe accident is relatively low in LATVs, wheelchairs still need to be secured to reduce risk of injury to passengers [2,12-14]. A computer simulation study conducted to assess wheelchair and occupant kinematics under braking and turning conditions at an acceleration level of $<1 \mathrm{G}$ demonstrated the need for wheelchair securement in LATVs [15]. This study indicated that inadequately secured wheelchairs may easily tip over when an LATV turns. A more recent in-vehicle study supports these findings and shows that most unsecured wheelchairs exposed to emergency braking or turning inside an LATV will slide forward or tip over, respectively, potentially causing injury to wheelchair users and other passengers [14].

Wheelchair securement in LATVs is needed to reduce occupant injury risk; however, wheelchair securement systems also need to provide adequate comfort, usability, and independent use to improve their use and effectiveness. To provide increased usability and independent use, systems can be designed for use solely in LATVs, which, because of the reduced likelihood of severe crash and routine low forces experienced on LATVs, can be less design restrictive. Alternative wheelchair securement systems have been developed to improve usability and independent use [1618]. Rear-facing wheelchair passenger (RF-WP) systems that provide independent use and wheelchair containment are widely used in LATVs in Europe and Canada and recently started appearing in the United States [18-19]. Autodocking systems for use on LATVs have been devel- oped and tested with some success [16-17]. Autodocking systems allow the wheelchair to dock a wheelchair adaptor to a receptacle that is securely attached to the floor of the vehicle. Autodocking systems, though popular in private vehicles, are not yet widely used in LATVs.

A state-of-the-science workshop on wheelchair transportation safety identified that the top-ranked strategy for moving forward with alternative wheelchair securement concepts that improve usability and independent use in public transit was to conduct broad-based, private, and federally sponsored demonstration projects of these technologies with high stakeholder involvement and wide dissemination of results [20]. This article responds to the need identified by the workshop. No prior studies have been conducted on the usability of autodocking or RF-WP system designs compared with the 4-point tie-down system. We chose a structured approach to usability testing, including a heuristic component to obtain information from both wheelchair users and LATV operators. This article focuses on findings obtained from wheelchair-seated passengers only.

\section{OBJECTIVES}

The primary objective of this study was to evaluate the usability, comfort, and independent use of two prototype wheelchair securement systems compared with the 4-point tie-down system for passengers seated in a manual wheelchair, power wheelchair, or scooter while riding an LATV. Additionally, this study sought input from wheelchair and scooter users on how to improve LATV securement systems.

\section{METHODS}

\section{Wheeled Mobility Devices}

We selected two commonly used wheelchairs and one scooter (hereafter referred to collectively as "wheelchairs") for this study. We made an effort to select wheelchairs that complied with voluntary standards (Rehabilitation Engineering and Assistive Technology Society of North America Wheelchair Standard 19 [RESNA WC19] or International Organization for Standardization [ISO] 7176-19) and could be easily adapted to work with the wheelchair securement systems to be evaluated [21-22]. To be compatible with the test systems and setup, each wheelchair needed to be equipped with at least four tie-down securement points, an 
autodocking adaptor meeting specifications of ISO 10542-3 for universal design interface geometry (UDIG) [23], and a wheelchair-anchored pelvic restraint. Wheelchairs that comply with RESNA WC19 and ISO 7176-19 provide four easily accessible securement points on the frame to attach tie-down straps. Additionally, RESNA WC19-compliant wheelchairs are equipped with anchors for a crash-tested pelvic restraint. The three wheelchairs chosen were-

1. TDX SP power wheelchair (Invacare; Elyria, Ohio). RESNA WC19 compliant and equipped with four tiedown securement points and a frame-mounted pelvic belt. With assistance from Invacare, a prototype UDIG adaptor was designed, fabricated, and installed onto the wheelchair (Figure 1).

2. Quickie 2 manual wheelchair (Sunrise Medical; Longmont, Colorado). ISO 7176-19 compliant and equipped with four tie-down securement points. With assistance from Sunrise Medical, a prototype UDIG adaptor was installed on the wheelchair. A wheelchair-anchored pelvic restraint was also added (Figure 2).

3. Amigo RD three-wheel electric scooter (Amigo Mobility International; Bridgeport, Michigan). With assistance from Amigo Mobility International, the scooter was equipped with two front aluminum tie-down securement

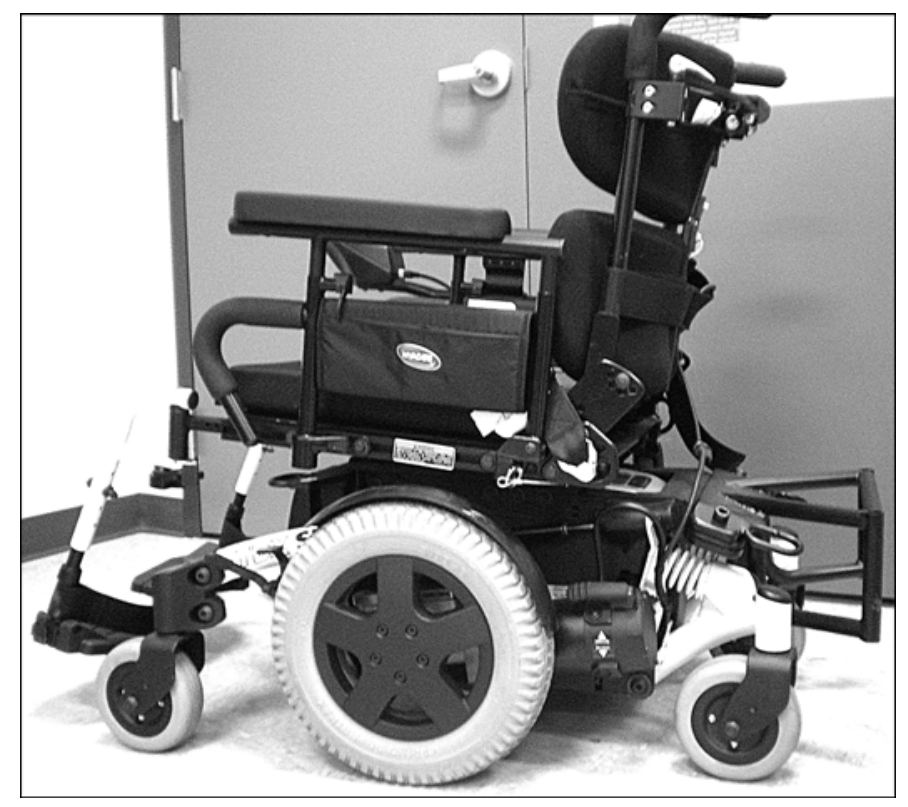

Figure 1.

TDX SP power wheelchair (Invacare; Elyria, Ohio) equipped with four tie-down securement points, universal design interface geometry adaptor, and frame-mounted pelvic restraint. points, a prototype UDIG adaptor with two integrated rear tie-down securement points, and a UDIG-anchored pelvic restraint (Figure 3).

Pelvic restraints were prototypes provided by Bodypoint, Inc (Seattle, Washington) and Q'Straint (Fort Lauderdale, Florida). None of the modified components (UDIG adaptors or wheelchair-anchored pelvic restraints) were strength tested before in-vehicle testing. However, materials and anchor points of sufficient strength to withstand low acceleration forces were selected and best engineering practices were used.

\section{Wheelchair Securement Systems}

Three types of wheelchair securement systems were used in the study:

1. Four-point tie-down system. The commercially available, state-of-the-art system used for the trials complied with recommended practice Society of Automotive Engineers J2249 and consisted of four straps contained in self-tensioning retractors (QRT Deluxe retractable system [Q'Straint]) [7]. The LATV driver attached the

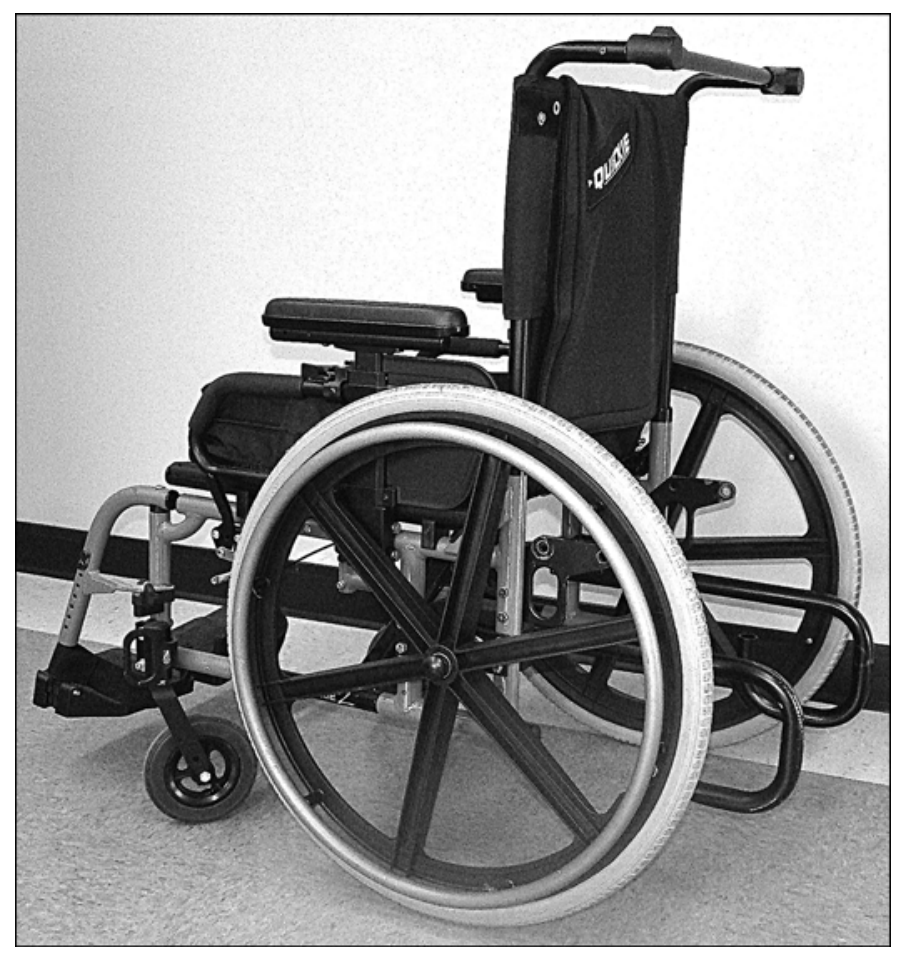

Figure 2.

Quickie 2 manual wheelchair (Sunrise Medical; Longmont, Colorado) equipped with four tie-down securement points, universal design interface geometry adaptor, and frame-mounted pelvic restraint. 


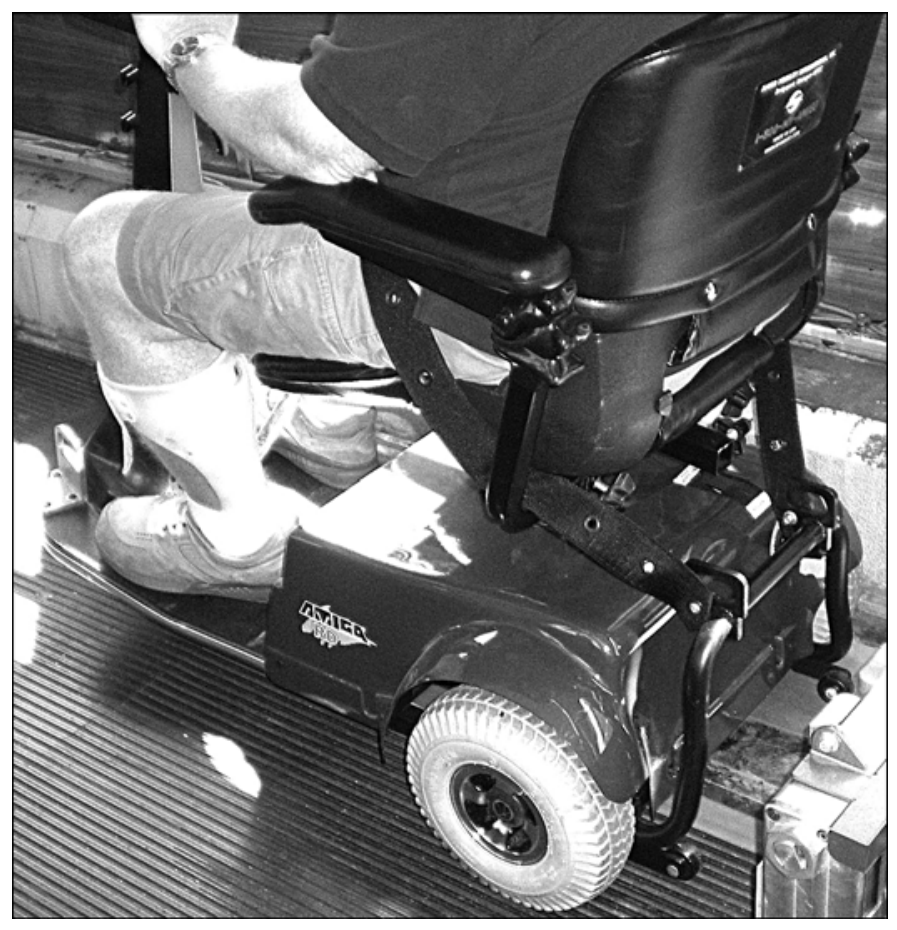

Figure 3.

Amigo RD three-wheel electric scooter (Amigo Mobility International; Bridgeport, Michigan) equipped with two tie-down securement points, universal design interface geometry adaptor (UDIG), and UDIGmounted pelvic restraint.

securement hook of each strap to one of the four wheelchair securement points: two straps to the front and two to the back (Figure 4). The retractors contained a manual tension mechanism that allowed the driver to tighten the straps at their discretion to further reduce wheelchair movement.

2. Autodocking system. The prototype forward-facing autodocking system was developed by the University of Pittsburgh (Pittsburgh, Pennsylvania) and Sure-Lok, Inc, (Bethlehem, Pennsylvania) in compliance with ISO 10542-3 [23-24]. The system consisted of a pneumatically powered engagement mechanism that automatically engaged with the UDIG adaptor on the rear frame of each wheelchair (Figure 5). The engagement mechanism allowed for approximately 2 in. $(50 \mathrm{~mm}$ ) of lateral misalignment during the docking process. The mechanism also allowed for up to $5^{\circ}$ of rotational misalignment during docking. Force-sensing plates detected when a contact synchronized displacement was applied by the UDIG adaptor located on the back of the rearwardmoving wheelchair and activated the engagement mecha- nism. To release the wheelchair from the autodocking system, the wheelchair user or LATV driver activated a wall-mounted $12 \mathrm{~V}$ electric switch. A manual release mechanism was available with this prototype but not evaluated in this study.

3. RF-WP system. The prototype RF-WP system was developed by the University of Pittsburgh and Q'Straint in compliance with the final voluntary standard ISO 10865-2 [25]. This system contained a forward excursion barrier (FEB) made up of a rear-facing head and backrest (Figure 6). A pneumatically activated arm (lateral barrier) on the aisle side of the vehicle rotated from a downward position to a $45^{\circ}$ position. The powered lateral barrier also moved sideways (laterally) in both directions to accommodate different wheelchair positions and widths. The wall side of the system had a pneumatically activated foam-covered contact plate approximately $25 \times 60 \mathrm{~cm}$ at $5 \mathrm{~cm}$ off the floor. The lateral position and wheelchair contact force of this plate was automatically synchronized with the position and movement of the aisle-side arm. To use the RF-WP system, a wheelchair user, facing the rear of the vehicle, backed up to the FEB. Once the wheelchair seat back or frame was positioned against the FEB, the driver activated the two lateral barriers. The aisle-side arm and the wall-side foam-covered plate moved laterally until they contacted the wheels and/or the frame with sufficient contact force to hold the wheelchair in place, even during unexpected LATV driving events. This system did not require additional wheelchair-mounted hardware (e.g., UDIG adaptor or securement points). To release the wheelchair from the system, the wheelchair user activated a wall-mounted switch, which disengaged both the aisle-side arm and wall-mounted plate, allowing the user to exit the system. Although this prototype did not include automatic activation of the lateral barriers and a manual release mechanism that the wheelchair occupant could operate, future versions will include these features.

\section{In-Vehicle Test Setup and Driving Course}

The Port Authority of Allegheny County, Pennsylvania, provided a $40 \mathrm{ft}$ Orion V high-floor LATV (Orion Bus Industries; Oriskany, New York) and a trained, licensed driver for testing purposes. The test vehicle had a front-mounted platform lift and seats were removed to install all three wheelchair securement systems. The 4-point tie-down system was placed behind the driver (Figure 4). The prototype autodocking system and prototype RF-WP system were 


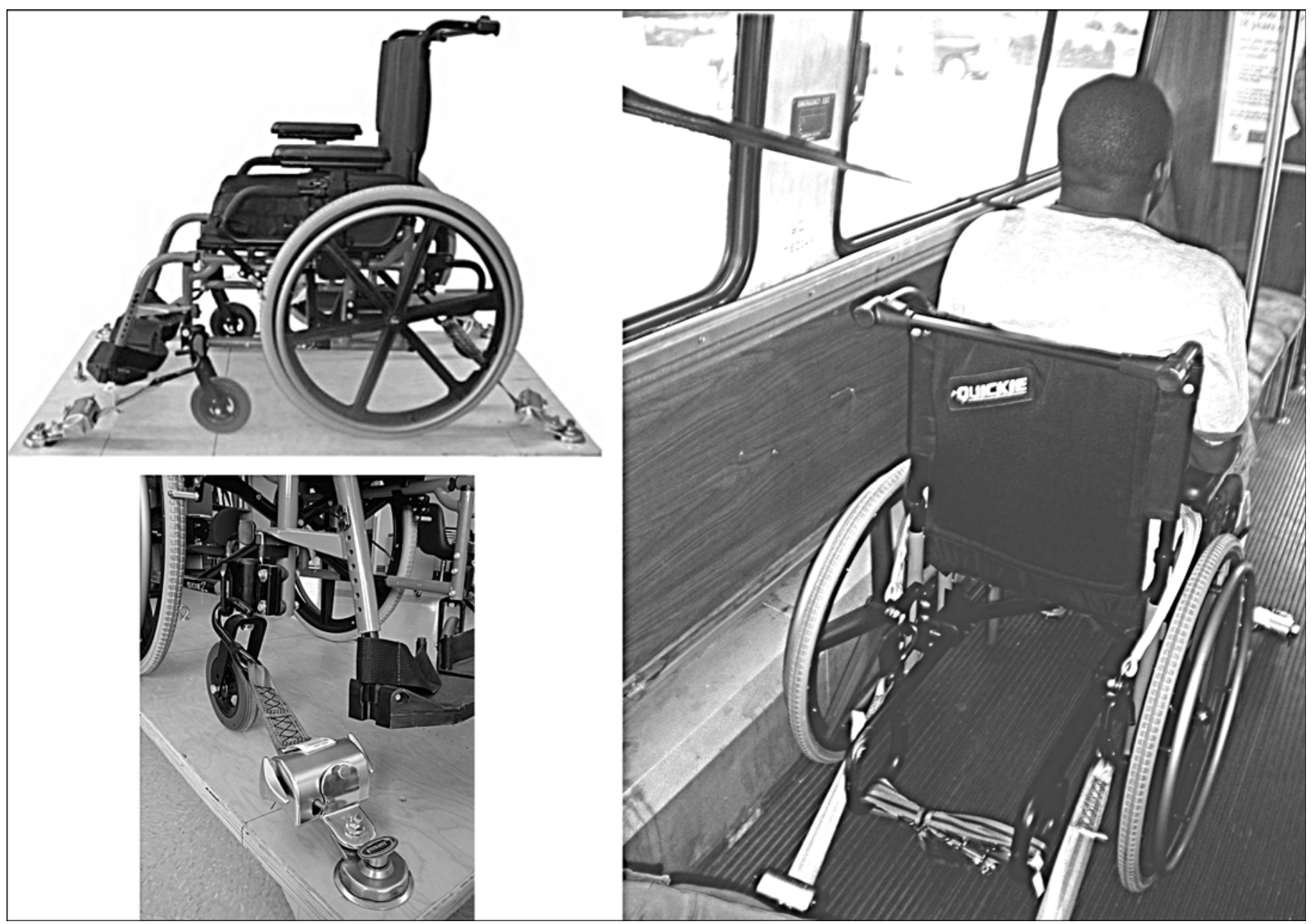

Figure 4.

Manual wheelchair secured with retractor-type, four-point tie-down system (Q'Straint; Fort Lauderdale, Florida).

placed on the nondriver side of the vehicle (Figures 5 and 6). The controls for the RF-WP and the autodocking systems were attached to the sidewall of the vehicle underneath the windows. Each system was equipped with a vehicle-mounted shoulder belt (Q'Straint) that could be anchored to a pin connector located on the wheelchairmounted pelvic belt.

Testing took place in the Oakland area of Pittsburgh, Pennsylvania, on an urban course representing typical driving conditions. The course consisted of multiple left and right turns, starts, stops, and steep inclines and declines. The maximum downhill grade of the course was 17 percent.

\section{Study Population}

By distributing flyers through local organizations that transport or serve wheelchair users, we recruited 20 partici- pants. In addition, we mailed flyers to Amigo Mobility International for distribution to local scooter users. Individuals eligible to participate in the study included adult males and females who sit in their wheelchair or scooter when riding in a vehicle. Participants needed to have the ability to transfer (with or without assistance) into a test wheelchair that was similar in setup to their own wheeled mobility device and be able to sit in the test wheelchair for the duration of the study (up to $3 \mathrm{~h}$ ). Because standard-size test wheelchairs were used for the study, individuals who used a wheelchair with a seat wider than 18 in. were excluded from the study. Prospective participants were also asked if their wheeled mobility device was modified or customized in any way (e.g., postural devices, headrest, tilt-inspace). Wheelchair users who required major modifications and customizations to provide for pressure relief or postural 


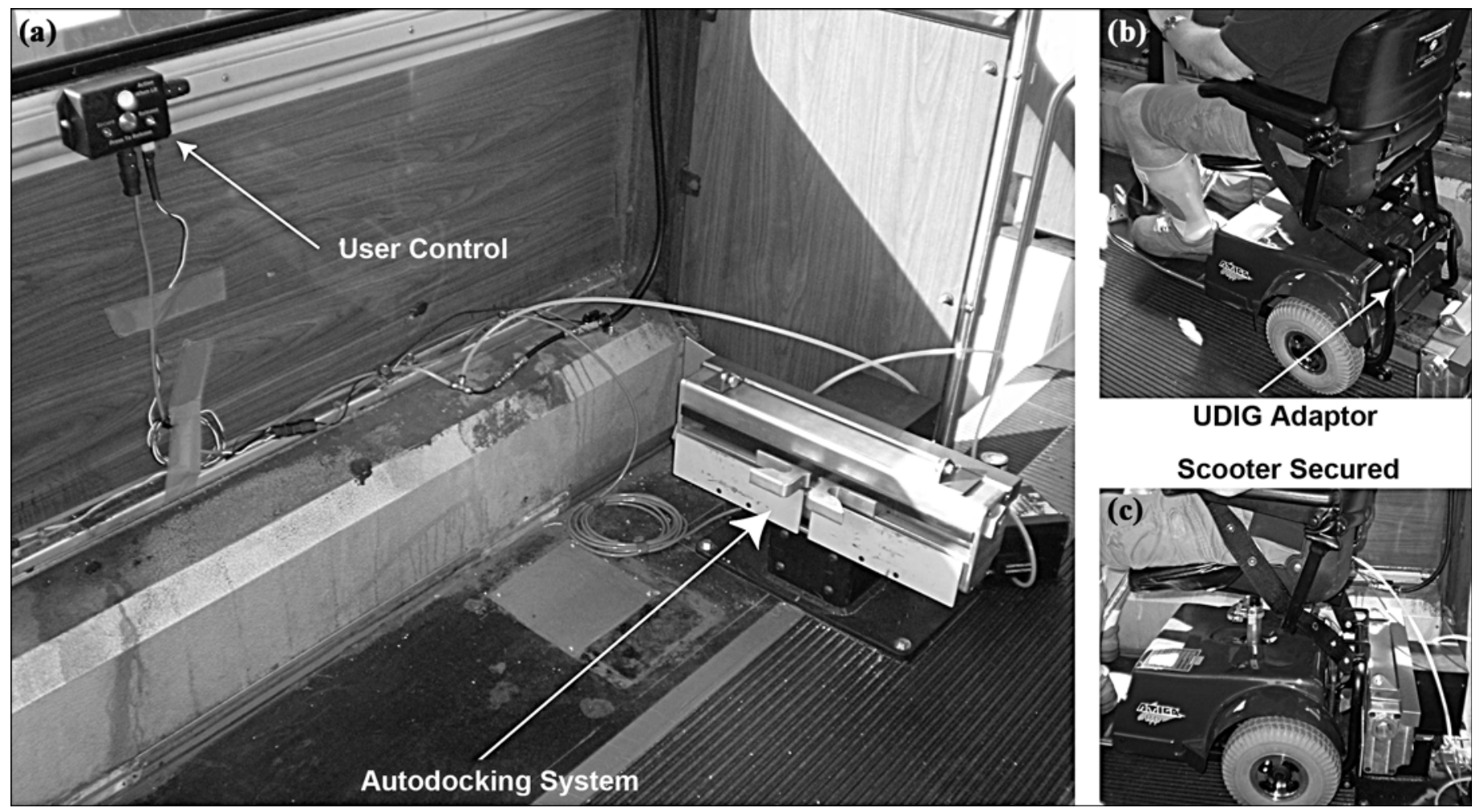

Figure 5.

(a) Autodocking system installed in large accessible transit vehicle. Scooter equipped with universal design interface geometry (UDIG) adaptor (b) backing up and (c) secured by autodocking system.

support were excluded from the study because the test wheelchairs could not be modified to optimally fit their needs. Study participation also required the ability to respond to survey questions.

\section{User Evaluation Method}

United Cerebral Palsy of Pittsburgh provided the facilities for conducting the logistics of the study. Testing took place over 5 weekdays in two shifts, morning and afternoon. For each shift (morning or afternoon), one manual wheelchair user, one power wheelchair user, and one scooter user were scheduled. Investigators filled empty spots so that participants did not feel awkward if they were the only study participant on the LATV and to give all participants a similar experience riding and maneuvering in and around other individuals on the LATV.

Before the in-vehicle trials, investigators explained the nature and purpose of the research study and the potential benefits and possible risks to each participant. Participants then transferred to one of three test wheelchairs that matched the type they regularly used, and we made adjustments to the test wheelchair to meet their postural needs. Next, an investigator introduced and explained each wheelchair securement system, and participants tried each system to get familiar with its function. Participants were randomly assigned to use one of the three securement systems for their first trip. They then rotated clockwise through the three systems until all three had been experienced. Participants were observed while they entered and exited each wheelchair system and, if not automatic, while having their wheelchair secured and/or belt restraints positioned. For safety, the use of a wheelchair-mounted pelvic restraint was mandatory during all driving tests. The participants were informed that use of the vehicle-mounted upper-torso restraint was optional and, therefore, provided only on request. The optional use of the torso belt was consistent with Federal regulations in the United States [1].

We developed a questionnaire to determine participants' personal opinions regarding their experience traveling in an LATV while seated in their wheelchair. After a 15-minute test ride, study participants answered questions 


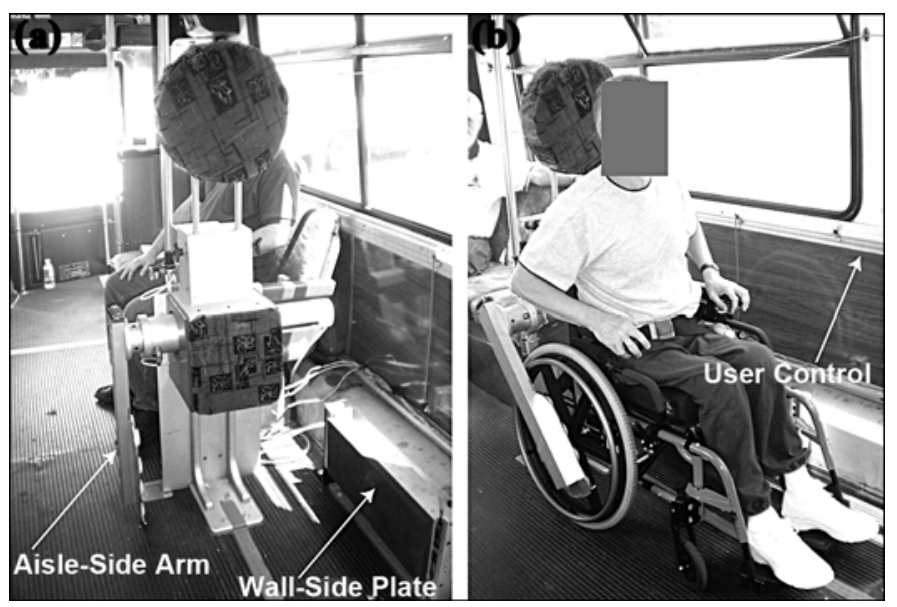

Figure 6.

(a) Rear-facing wheelchair passenger (RF-WP) system with aisle-side arm and wall-side plate and (b) example of manual wheelchair positioned in RF-WP.

on the safety, usability, and comfort of the securement system. Digital video and photographs also documented how participants used the securement systems.

The first part of the survey covered questions on demographics, transportation characteristics, and ratings (by those participants who rode seated in their wheelchair in LATVs) of a normal LATV wheelchair securement experience using a scale from 1 to 10 , where $1=$ very poor and $10=$ excellent (Appendix, available online only). The second part of the survey asked for identical ratings on the ease of use, safety, independent use, and comfort of the three wheelchair securement systems used in the study. Participants also identified what they liked and disliked about each system; which system they liked best and least; and which system they felt was most and least safe, easiest and hardest to use, most and least comfortable, took the most and least time to use, and could be used most and least independently. Participants also answered whether their favorite system would increase their use of LATVs, said how much they would be willing to pay to alter their wheelchair to be compatible with the system, and suggested system improvements (Appendix, available online only).

\section{Data Analysis}

Data are summarized as the means for continuous variables and frequencies for categorical variables. For openended questions, two investigators independently created categories to quantify responses and reconciled inconsis- tencies. Characteristics of participants (age and sex) and wheelchair type were compared using Fisher exact tests. Ratings of the three securement system experiences with respect to safety, independent use, ease of use, and comfort were compared using a within-subject repeated measures analysis of variance (ANOVA). The test ratings were also compared with the participant pre-study ratings of previous LATV experience using Wilcoxon signed rank tests. Change scores were created for each participant for each of the three tested securement systems by subtracting the securement system rating from the corresponding rating by the participant of his or her prestudy LATV experience. The change scores were summed across all rating categories for each participant. The means of the summed change scores for each of the three securement systems were compared using a within-subjects repeated-measures ANOVA. All tests were two-sided and $p<0.05$ was considered statistically significant. Data were analyzed using SPSS version 17.0 (Cary, North Carolina).

\section{RESULTS}

\section{Participant Characteristics}

The study population consisted of 20 individuals who use a wheelchair as a primary means of mobility (Table 1). Fourteen individuals (70\%) were male and six (30\%) were female. Eight (40\%) were $\leq 50$ years old and 12 (60\%) were $>50$ years old. Eight (40\%) participants used a power wheelchair to test the securement systems, seven (35\%) used a manual wheelchair, and five (25\%) used a threewheel electric scooter. When wheelchair type (manual, power, and scooter) was compared with sex and age category, no significant differences were found.

\section{Travel Characteristics}

The survey collected information on how often participants traveled in LATVs, paratransit vehicles, personal vans, and personal cars (Table 2). Five participants (25\%) travelled daily in an LATV, two (10\%) weekly, one (5\%) monthly, and four (20\%) less than monthly. For eight participants (40\%), the daily mode of transportation was a personal van or car. All of the participants who ride LATVs and paratransit vans remain seated in their wheelchairs. Slightly over 70 percent of those who travel in a personal van also remain seated in their wheelchair. Seventy-five percent of those who travel in a personal car always transfer to a vehicle seat. Of the 12 participants who remain seated in a wheelchair on LATVs, 10 (83\%) 
never have their wheelchair secured. In contrast, 10 of the 11 participants (91\%) who remain in their wheelchairs on a paratransit vehicle and all participants who remain seated in their wheelchair while traveling in personal vans reported using wheelchair securement.

\section{Securement System Likes and Dislikes}

After participants used a specific securement system and evaluated its performance during a 15 min bus ride, they listed what they liked and disliked about each wheelchair securement system. Like and dislike statements from participants were placed in seven categories. Figures $\mathbf{7}$ and $\mathbf{8}$ list the likable and nonlikable features, respectively, named for the 4-point tie-down, autodocking, and RF-WP systems.

A sense of stability was named as a likable aspect by 30 percent of participants for the 4-point tie-down and autodocking systems and by 40 percent of participants for the RF-WP system. Comfort while riding using the autodocking system was reported by 40 percent of participants. Independent use was a likable aspect indicated by

Table 1.

Participant demographics $(N=20)$. Data shown as $n(\%)$.

\begin{tabular}{|c|c|c|c|c|}
\hline Characteristic & $\begin{array}{c}\text { No. of } \\
\text { Participants }\end{array}$ & $\begin{array}{c}\text { Power } \\
\text { Wheelchair } \\
\text { Users }^{*}\end{array}$ & $\begin{array}{c}\text { Manual } \\
\text { Wheelchair } \\
\text { Users }\end{array}$ & $\begin{array}{l}\text { Scooter } \\
\text { Users }\end{array}$ \\
\hline \multicolumn{5}{|l|}{$\begin{array}{l}\text { Sex } \\
\text {. }\end{array}$} \\
\hline Male & $14(70)$ & $7(50)$ & $4(29)$ & $3(21)$ \\
\hline Female & $6(30)$ & $1(17)$ & $3(50)$ & $2(33)$ \\
\hline \multicolumn{5}{|l|}{ Age (yr) } \\
\hline$\leq 25$ & $1(5)$ & $1(100)$ & $0(0)$ & $0(0)$ \\
\hline $26-50$ & $7(35)$ & $3(43)$ & $4(57)$ & $0(0)$ \\
\hline$>50$ & $12(60)$ & $4(33)$ & $3(25)$ & $5(42)$ \\
\hline $\begin{array}{l}\text { Total by Wheelchair } \\
\text { Type }\end{array}$ & - & $8(40)$ & $7(35)$ & $5(25)$ \\
\hline
\end{tabular}

Table 2.

Participants traveling in large accessible transit vehicles (LATVs), paratransit vehicles, personal vans, and personal cars $(N=20)$. Data shown as $n(\%)$.

\begin{tabular}{llcll}
\hline $\begin{array}{c}\text { Travel } \\
\text { Frequency }\end{array}$ & LATV & $\begin{array}{c}\text { Paratransit } \\
\text { Vehicle }\end{array}$ & $\begin{array}{c}\text { Personal } \\
\text { Van }\end{array}$ & $\begin{array}{c}\text { Personal } \\
\text { Car }\end{array}$ \\
\hline Daily & $5(25)$ & $1(5)$ & $4(20)$ & $4(20)$ \\
Weekly & $2(10)$ & $3(15)$ & $1(5)$ & $1(5)$ \\
Monthly & $1(5)$ & $4(20)$ & $2(10)$ & $1(5)$ \\
<Monthly & $4(20)$ & $3(15)$ & $0(0)$ & $3(15)$ \\
\hline \hline
\end{tabular}

40 percent of participants for the autodocking system. Ease of use was stated by 50 and 60 percent of participants as a positive feature of the RF-WP and autodocking systems, respectively. Finally, a sense of safety and security was a likable aspect reported by 30,45 , and 50 percent of participants for the autodocking, 4-point tie-down, and RF-WP systems, respectively. Ten percent of participants commented that they liked the security added by the seat belt (lap and/or shoulder belt) during the ride.

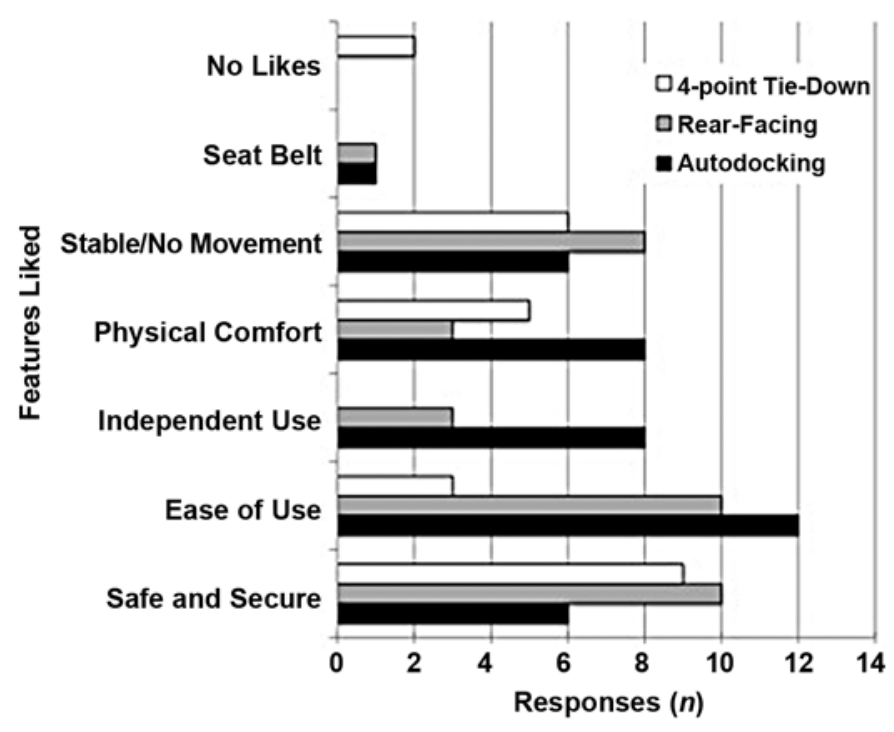

Figure 7.

Liked aspects of three securement systems.

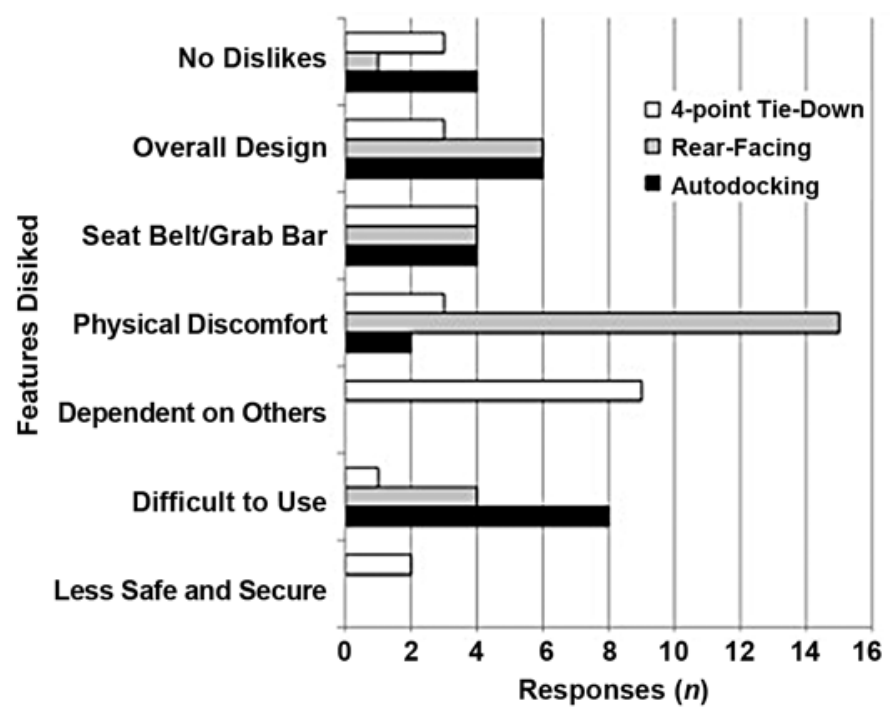

Figure 8.

Disliked aspects of three securement systems. 
Physical discomfort during the ride was a nonlikable feature reported by 75 percent of participants for the RF-WP system. Dependence on others when using the system was indicated as nonlikable by 45 percent of participants for the 4-point tie-down system. Difficult to use was mentioned by 40 percent of participants for the autodocking system. Overall design was identified as a nonlikable feature by 30 percent of participants for the autodocking and RF-WP systems. For the autodocking system, the design-related dislikes included statements about getting into the system and the lack of user feedback during the docking process, the fact that a piece of hardware needs to be mounted on the wheelchair for it to work, and the fact that the autodocking system control was confusing to some participants. For the RF-WP system, participants commented that the system took up too much space in the LATV and that the system may damage wheelchair spokes. Fifty percent of participants commented that the seat belt either didn't provide enough support or was undesirable, and 10 percent commented on the lack of available grab bars during the ride.

\section{Performance Rating}

After each in-vehicle evaluation of a wheelchair securement system, participants rated the system for various crite- ria related to riding experience on a scale from 1 to 10 , where $1=$ very poor and $10=$ excellent. Figure 9 lists the average rating of all 20 participants for the 4-point tie-down, autodocking, and RF-WP systems. Criteria rated low on the scale are identified as closer to the center point.

The average rating for safety during stops and turns was 9 across all three securement systems. Safety during vehicle accelerations ranged from 8.4 for the RF-WP system to 8.8 and 9.3 for the 4-point tie-down and autodocking systems, respectively. Overall safety during the ride ranged from 8.4 for the 4-point tie-down system to 9.1 and 8.6 for the autodocking and RF-WP systems, respectively. Ride comfort was rated lower for the 4-point tie-down (8.2) and RF-WP systems (7.9), with the autodocking system rated highest (9.1). Quick, independent, and ease of use were rated lower for the 4-point tie-down system (6.0, 3.5, and 5.2, respectively), and scored a 9, on average, for both the autodocking and RF-WP systems. Within-subject repeated-measures ANOVAs revealed that the 4-point tiedown system was rated significantly lower for quick, independent, and ease of use $(p<0.001)$. There were no significant differences between the three systems for comfort or any of the four safety criteria. Note that the "normal LATV experience" indicates the average rating by

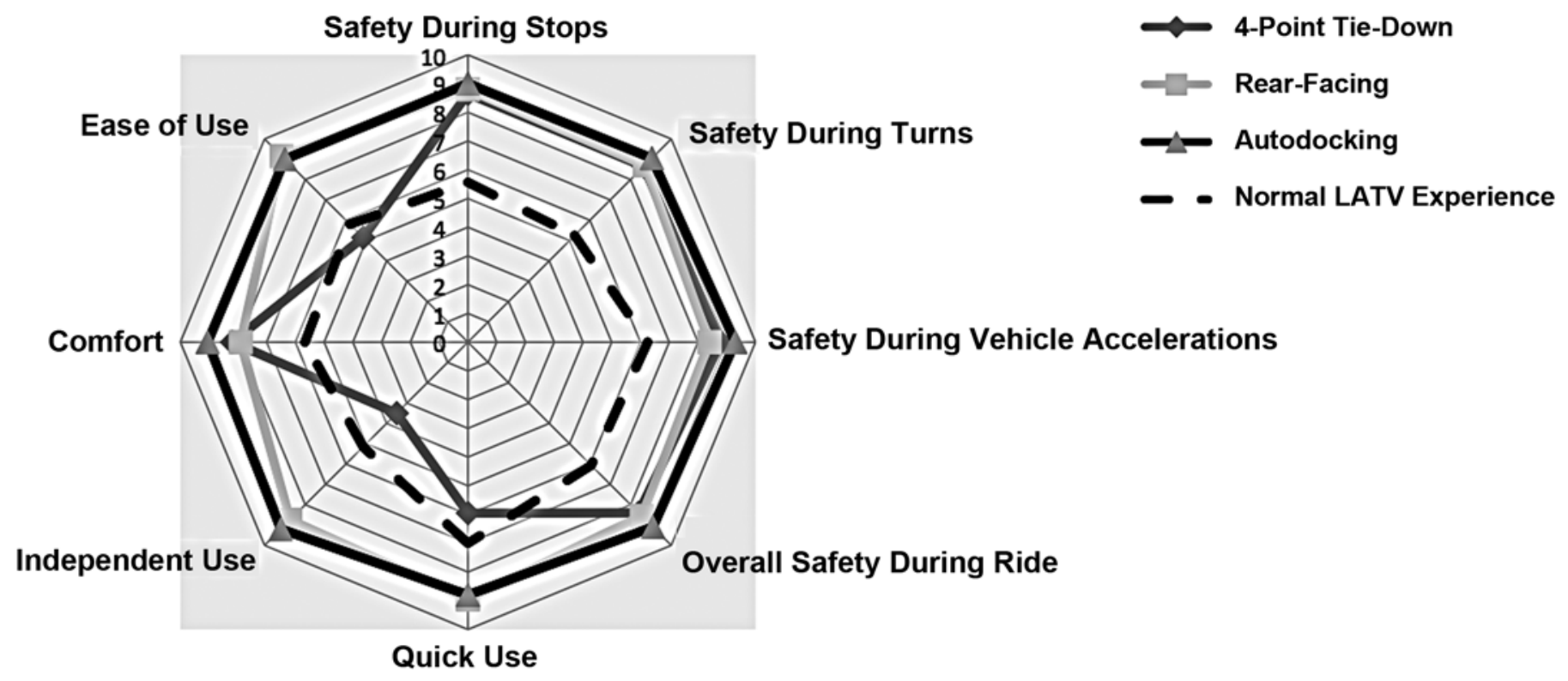

Figure 9.

Average riding experience ratings ( 1 = very poor and $10=$ excellent) of key user criteria for each of three test securement systems. Note: "Normal LATV experience” indicates average rating of their typical real-world riding experience by subset of participants who ride LATVs seated in wheelchairs. LATV = large accessible transit vehicle. 
the subset of participants who ride on LATVs seated in a wheelchair for their typical real-world riding experience.

The securement system ratings from the in-vehicle testing were also compared with the ratings provided by participants on his or her normal securement experience on a LATV (Figure 9). The 4-point tie-down system was not significantly different from the normal LATV experience for the ratings of quick, independent, and ease of use. The RF-WP and autodocking systems were significantly different from the normal experience for these criteria and better rated. Significant differences were found between the normal LATV experience and all systems for all safety ratings and comfort with the three test systems rated higher, with the exception of safety during acceleration for the RF-WP system.

Change scores were created for each participant for each of the three tested securement systems by subtracting the securement system rating from the participant's corresponding rating of his or her normal LATV transportation experience and then summed for each securement system. The 4-point tie-down system had a significantly lower average summed change score $(-13.62)$ than the autodocking and RF-WP systems: -24.25 and -21.88 , respectively $(p=0.004)$. The autodocking and RF-WP systems were not significantly different from each other.

\section{Overall Comparison of Securement Systems}

After participants had completed all three in-vehicle evaluations with each securement system, participants answered which systems they liked best and least, was most or least safe, was most difficult or easiest to use, was most or least comfortable to ride in, took most and least amount of time to get secured with, and was most or least independent to use. Figures $\mathbf{1 0}$ and $\mathbf{1 1}$ show the number of participants who chose each securement system for the positive and negative features listed.

Most liked and disliked. Fourteen participants (70\%) liked the autodocking system best, three liked the RF-WP system best, and two preferred the 4-point tie-down system. Participants stated the reasons they liked the autodocking system as quick, independent, easy, and intuitive to use and allowing forward-facing travel. Participants liked the RFWP system because it is easy to use, it is safe and secure, any wheelchair could use the system, no wheelchair hardware is required, and it has a headrest. Fourteen participants (70\%) liked the 4-point tie-down system the least because of the need for operator assistance, movement in the system, the time needed to get secured, and system nonuse. Six

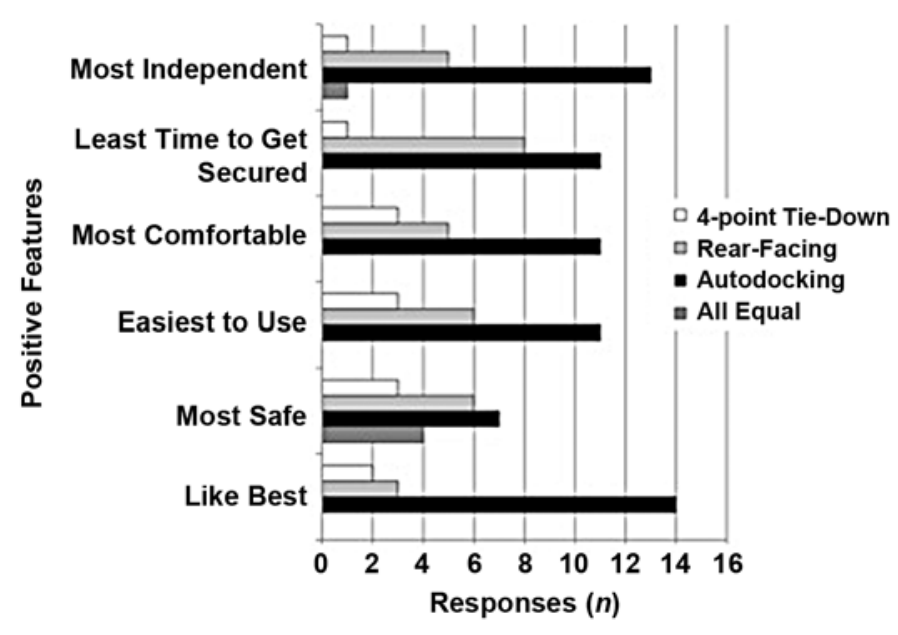

Figure 10.

Number of participants choosing each securement system for positive features listed.

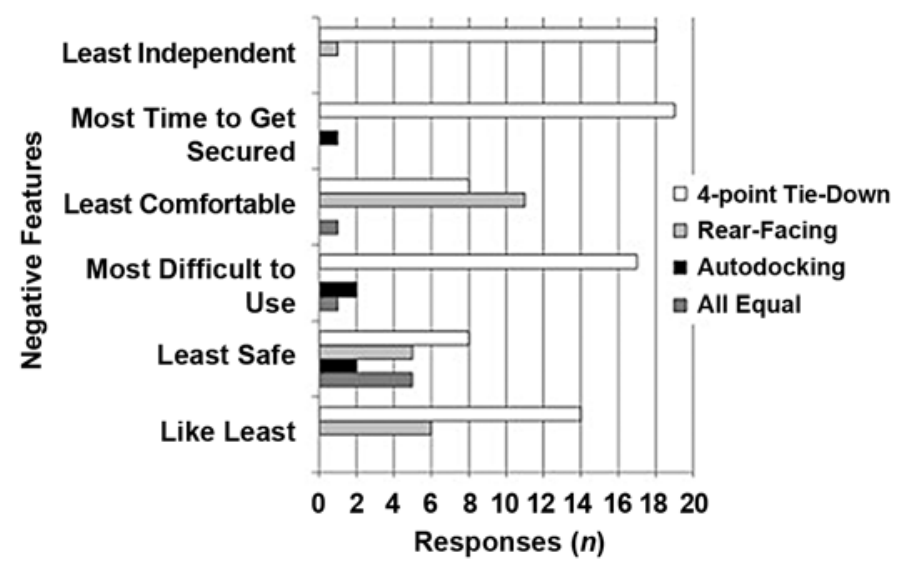

Figure 11.

Number of participants choosing each securement system for negative features listed.

participants liked the RF-WP system the least because passengers have to sit facing rearward, the system does not provide good upper-body support, and the driver has to activate and engage the system.

Safety. Seven participants ranked the autodocking system as most safe, six ranked the RF-WP system as most safe, and three ranked the 4-point tie-down as most safe. Four participants ranked all systems as evenly safe. Eight participants ranked the 4-point tie-down system as least safe, five ranked the RF-WP system as least safe, and two ranked the autodocking system as least safe. Five participants ranked all systems as evenly safe. Reasons participants 
thought the RF-WP was most safe included the fixed hold on the wheelchair allowing minimal movement, the solid backrest, and the stability the backrest can provide during vehicle braking. Reasons that participants thought the autodocking system was the most safe included the secure engagement with the wheelchair and the minimal movement of the wheelchair. Participants who ranked the 4-point tiedown system as most safe indicated that it was a familiar system and has four points that anchor the wheelchair to the vehicle floor.

Ease of use. Eleven participants ranked the autodocking system as easiest to use, whereas six participants ranked the RF-WP system as easiest to use. Seventeen participants ranked the 4-point tie-down system as most difficult to use because of the need for assistance from an operator when using this system. Two participants ranked the autodocking system as most difficult to use because of difficulties lining up the wheelchair and backing up when on a downhill slope.

Comfort. Eleven participants ranked the autodocking system as most comfortable to ride in because they were facing forward, could use it independently, could secure the system themselves, and could release quickly and easily. Five individuals ranked the RF-WP system as most comfortable because of the back support, steady system, and possible eye contact with other passengers. Three participants ranked the 4-point tie-down as most comfortable to ride in. Eleven individuals ranked the RFWP system as least comfortable because of facing backward during the ride, feelings of motion sickness, and upper-body movement. Eight participants ranked the 4-point tie-down system as least comfortable because of a less secure system and the operator invading personal space during securement.

Securement time. Eleven participants ranked the autodocking system as taking the least time to get secured, whereas eight individuals ranked the RF-WP station as taking the least time. Nineteen participants ranked the 4-point tie-down system as taking the most time.

Independent use. Thirteen participants ranked the autodocking system as most independent to use versus five participants ranking the RF-WP system as most independent. Eighteen participants ranked the 4-point tiedown system as least independent. One participant ranked the 4-point tie-down system as most independent to use because this individual could secure his or her own wheelchair with it. One participant ranked all systems as evenly independent to use.
General questions. When asked if their use of LATVs would increase if their favorite wheelchair securement system were available, 9 out of 19 individuals indicated that it would. Individuals stated that their favorite systems would make it easier to ride the LATV, would not slow it down, would not burden other travelers, and would be safer when riding bumpy routes with hills and turns.

Participants also said how much they were willing to pay out of pocket to alter their wheelchair to allow use with a wheelchair securement system such as the autodocking system. Four cost options were offered: nothing, less than $\$ 100$, between $\$ 100$ and $\$ 250$, and more than $\$ 250$. Seven participants indicated that they would not pay an additional cost to equip their wheelchair to work with a securement system. Nine individuals stated they would pay less than $\$ 100$ and four individuals were willing to pay between $\$ 100$ and \$250. Participants stated that an adaptor, like the autodocking system UDIG adaptor, should be designed as part of the wheelchair or come as a safety feature with the wheelchair. Two individuals (who both used manual wheelchairs) did not want additional hardware on their wheelchair unless they had no other option or the adaptor was small and retractable.

System improvements. After each securement evaluation, participants suggested how the system they just used could be improved. Figure 12 lists the key improvements participants listed for each of the three systems. Some improvements are only applicable to one

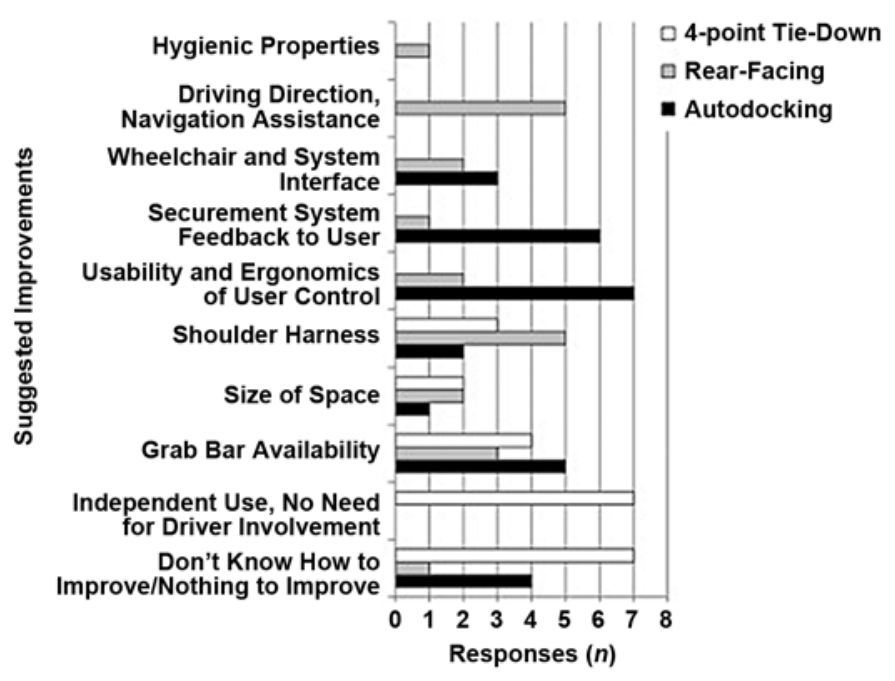

Figure 12.

Suggested improvements for 4-point tie-down, autodocking, and rearfacing wheelchair passenger systems. 
specific securement system, such as the change in driving direction (RF-WP system only) and need for independent use (4-point tie-down system only).

Participants answered an open-ended question regarding other features not available on the three securement systems that they thought could be useful. Some of the features mentioned included horizontal and vertical grab bars, control instructions, emergency release buttons, and a mirror (to allow users to look behind them when using the RFWP system).

\section{Four-Point Tie-Down System}

Seven participants suggested that the 4-point tiedown system needs to be redesigned so that it can be used by wheelchair users themselves. Another seven participants indicated that they do not know how to improve it, or that they can suggest nothing to improve the system. Four participants suggested adding a grab bar to the 4-point tie-down system and three expressed the need for a better upper-torso restraint. Two individuals commented on the (small) size of the 4-point tie-down system and that they would like to see a larger wheelchair space in vehicles that have 4-point tie-down systems installed.

\section{Rear-Facing Wheelchair Passenger System}

The three improvements mentioned most for the RFWP system were changing the driving direction and adding route assistance $(n=5)$, making an upper-torso restraint available $(n=5)$, and adding a grab bar $(n=3)$. Participants would like to face forward and/or have a rearview mirror or have stop announcements made available to help passengers locate where they are going. Two participants would like to see the interface between wheelchair and system improved so that wheel spokes cannot be damaged by the system's lateral clamping mechanism. Two participants would like more maneuvering and sitting space in the RF-WP system, especially if the passenger space is designed for up to two wheelchair passengers (one forward facing and the other rear facing). Two participants would like to see an improved release control; text should be added and colors should be more distinct. One user commented on making the fabric-covered headrest more hygienic. Another user suggested a feature to better guide wheelchair users backing into the system.

\section{Autodocking System}

Seven participants would like improvements to the disengage control on the autodocking system. The exist- ing control box has a light that indicates whether the system is active. This indicator was often mistaken for a button. Six participants would like improved user feedback, so that users are better guided into the system and receive confirmation when it is properly engaged. Five participants expressed the need for a grab bar and four participants did not know how to improve the system or could not suggest improvements. Three participants commented on the wheelchair interface design with the autodocking system (UDIG adaptor) so that it does not alter the wheelchair footprint. Two participants would like improvements to the shoulder harness and one participant expressed the need for a larger securement space. One participant wanted the wheelchair to back up into the docking system farther (deeper) before the system activates and engages the UDIG adaptor and for the system to have an accessible manual release.

\section{DISCUSSION AND CONCLUSIONS}

This is the first study of its kind to evaluate users' opinions on various types of wheelchair securement systems for use in LATVs. Previous studies collected kinematic data on wheeled mobility devices within wheelchair systems or simulated safety by using anthropomorphic test devices $[14-15,18]$. To adopt new technologies into society, it is important to obtain user feedback early in the design process; therefore, user testing is a critical step for product success and adoption. This study asked for feedback not only from manual wheelchair users but also individuals with power wheelchairs and scooters. Power wheelchairs and scooters are especially well-known for difficulty when tie-down systems secured by vehicle operators are being used.

Our results concur with that of other investigators $[3-5,26]$ and indicate that people who travel in LATVs often do not transfer from their wheelchair into a bus seat. The fast pace of LATV transportation is not favorable for allowing standing passengers enough time to sit, let alone allow wheelchair passengers time to transfer to a seat. The rather fast pace of stopping and exiting and boarding passengers does not allow for lengthy individual treatment, even if this would mean a safer ride. In fact, many LATV passengers only ride for a few stops, which makes seat transfer or wheelchair securement even less convenient. 
Four-point tie-down systems are required by ADA regulations and, therefore, are the most commonly available systems on LATVs [1]. The ADA calls for the provision of these tie-downs and occupant restraints on LATVs as well as trained operators to use these systems, but ADA regulations do not require their use [1]. The reported lack of use of wheelchair securement on LATVs by our participants is similar to reports in the literature that wheelchairs on LATVs are not secured with existing wheelchair securement systems [2-3,26]. This could be because of equipment issues, operator training and practices, or user preference. Results from our survey give some insight into this lack of use: the 4-point tie-down system was rated significantly lower than the two prototype systems for quickness, independence, and ease of use. Fourteen participants (70\%) liked the 4-point tiedown system the least because it was the least independent, the most difficult, and required the most time.

This lack of use during routine travel and emergency maneuvers can lead to increased injury caused by wheelchairs tipping or rotating and riders subsequently falling from their wheelchairs. Shaw found that "few injuries and fatalities occur on transit buses;” however, “abrupt braking or turning occur frequently and are associated with half of onboard passenger injuries” [9]. Additionally, Frost and Bertocci investigated 115 wheelchair-related incidents on LATVs from one transit organization during a 5-year period [2]. Incidents involving wheelchair tipping and/or wheelchair riders falling occurred most frequently and were associated with activities at the wheelchair securement system in 19 percent of the cases. Incidents that occurred when the LATV was moving were more likely to occur during normal driving conditions than during emergency maneuvers. Improvements in securement system design are clearly needed to facilitate their use by wheelchairseated passengers in the fast-paced public transit environment. Systems need to be designed for quickness, independence, and ease of use, which means meeting the needs of the ultimate end user-the passengers seated in wheelchairs.

This study evaluated two alternatives to the 4-point tie-down system designed to improve independence and ease of use. The autodocking system met the most positive features listed in Figure 10, and 70 percent of participants liked it best. Participants liked the comfort, stability, ease of use, independent use, and forward-facing orientation of the autodocking system; however, this system was difficult to use for some. The autodocking system requires hard- ware attached to the back of the wheelchair and requires users to drive backward into the system. It also relies on some degree of alignment or the system may not engage immediately. This can create user difficulty and confusion as to when the wheelchair is properly aligned and safely secured. Therefore, participants identified improvements for the autodocking system as usability and system feedback and that the system control needs to be placed within reach of the rider and designed to be more intuitive. Finally, the use of a shoulder belt meant this system could not be used independently if this additional restraint was chosen.

RF-WP systems are being used successfully in Europe, Canada, and several trial locations in the United States. Study participants liked the stability, ease of use, and security that the RF-WP system provided. The fact that the system did not require any specific additional hardware was another positive feature highlighted. A rather large group (75\%), however, named "discomfort" as a problem with the RF-WP system, 30 percent liked this system the least, and 55 percent rated it the least comfortable. Reasons for discomfort included not only motion sickness during a rearfacing ride, but also an uncontrollable rocking motion induced to the participant's body during rear-facing travel and during vehicle braking and accelerating. Safety during acceleration was not rated significantly better for the RFWP system over the normal LATV experience, likely because of the unstable torso movements reported by participants. Although RF-WP systems are available and successfully used in public transportation, rear-facing travel may not be the optimal solution for those passengers that experience vertigo. To improve RF-WP systems, participants suggested the addition of upper-body support, improved usability through better aids to help navigate the wheelchair into the system, and improved indication of upcoming stops.

The 4-point tie-down test system was a state-of-the art system applied using all four tie-downs attached to RESNA WC19-compliant securement points on the wheelchairs. This presents the optimal setup for this type of system. Since this is the same type of system used in most LATVs, it is not unexpected that there was no difference between the participants' ratings for their normal LATV experience and the 4-point tie-down test system for quickness, independence, and ease of use. The RF-WP and autodocking prototype systems were significantly different from the normal experience for these criteria and better rated. The normal LATV experience was rated significantly lower 
for comfort and all but one safety rating than the three test systems. Yet there was no significant difference between the 4-point tie-down test system and the two prototype systems for these ratings. The difference between these comfort and safety ratings of the normal LATV experience and all test systems, including the 4-point tie-down system, was likely because the actual use of 4-point tie-down and a lap belt in the 4-point test system setup; 83 percent of respondents who ride on LATVs indicated they did not use securement. Despite improvements to the 4-point tie-down system offered by proper securement techniques, the average summed change score between the normal and test experience ratings was significantly less for the 4-point tiedown system, indicating less of an improvement over the normal experience than the RF-WP and autodocking systems offered.

Alternative solutions need to be developed in the form of forward-facing securement systems that do not require additional mounted hardware and that can be independently used by the majority of wheelchair passengers. The system should be suitable for an environment limited to low acceleration forces and prevent manual wheelchairs, power wheelchairs, and scooters from movement during the ride. The system should also provide the occupant with independent and easy means to prevent seat sliding or falling during vehicle turns and stops. Several study participants suggested adding a handhold to provide upper-body stability, such as a horizontal or vertical grab bar.

The relative novelty to the participants of rear-facing travel, the RF-WP system, the autodocking system, and (for some participants) riding in a LATV may have had an effect on participant responses. During the in-vehicle study, participants wore a wheelchair-mounted pelvic belt to prevent accidental sliding from their wheelchair seat during the bus ride. The use of a shoulder belt was optional and only a few participants chose to use it during the ride. Use of a pelvic and optional shoulder belt may have influenced some of the study findings related to system safety, security, and ride comfort.

Although the first assignment to evaluate a securement system by study participants was done at random, the clockwise rotation through securement systems may have induced a sequencing effect and could have affected how some participants answered questions at the end of one securement system evaluation.

The knowledge gained from observations and responses from study participants will be used to design improved securement systems for use on LATVs. The findings will also be communicated to wheelchair tie-down and occupant restraint system manufacturers to optimize forward- and rear-facing wheelchair securement systems.

\section{ACKNOWLEDGMENTS}

\section{Author Contributions:}

Study concept and design: L. van Roosmalen, D. Hobson. Acquisition of data: M. Turkovich, D. Hobson, L. van Roosmalen, E. Porach, P. Karg.

Analysis and interpretation of data: L. van Roosmalen, P. Karg. Drafting of manuscript: L. van Roosmalen, P. Karg, M. Turkovich. Critical revision of manuscript for important intellectual content: L. van Roosmalen, P. Karg.

Statistical analysis: P. Karg, L. van Roosmalen.

Obtained funding: L. van Roosmalen, D. Hobson, P. Karg. Administrative, technical, or material support: E. Porach. Study supervision: L. van Roosmalen, D. Hobson.

Financial Disclosures: The authors have declared that no competing interests exist.

Funding/Support: This material was based on work supported by the Department of Education, the National Institute on Disability and Rehabilitation Research (NIDRR), and the Rehabilitation Engineering Research Center on Wheelchair Transportation Safety (grant H133E060064). The autodocking system prototype was designed and developed by the University of Pittsburgh with industry support provided by Sure-Lok, Inc, under the National Institutes of Health Small Business Technology Transfer (grant 2R42HD34641-02). The RF-WP prototype was designed and developed with support from the NIDRR by the University of Pittsburgh with industry support from Q'Straint, Inc.

Additional Contributions: We thank the Port Authority of Allegheny County, Pennsylvania, for providing a vehicle, securement system installation, and drivers. We acknowledge BodyPoint, Inc; Q’Straint; Invacare; Amigo Mobility International; Sunrise Medical; and SureLok, Inc, for their support with designing prototypes; manufacturing components; and donating wheelchairs, securement systems, and seat belts. We also thank United Cerebral Palsy of Pittsburgh for use of their facilities during the study and Dr. Ana Allegretti for her assistance with wheelchair fittings. Dr. van Roosmalen is now at LINC Design, LLC, Verona, Pennsylvania; Dr. Turkovich has graduated and no longer works in this research field; and Dr. Hobson has retired.

Institutional Review: We obtained approval from the University of Pittsburgh Institutional Review Board (PRO08010172). All participants provided informed consent and permission to record digital photographs and video.

Participant Follow-Up: The authors do not plan to inform participants of the publication of this study. However, participants have been encouraged to check the study Web site (http://www.rercwts.org) for updated publications.

Disclaimer: The opinions expressed herein are from the authors and do not necessarily represent those of the NIDRR. 


\section{REFERENCES}

1. Part 37-Transportation services for individuals with disabilities (ADA). In: Americans with Disabilities Act. Washington (DC): Federal Transit Administration; 2007. p. 374-551.

2. Frost K, Bertocci G. Retrospective review of adverse incidents involving passengers seated in wheeled mobility devices while traveling in large accessible transit vehicles. Med Eng Phys. 2009;32(3):230-36. [PMID: 19395304$]$

3. Buning ME, Getchell CA, Bertocci GE, Fitzgerald SG. Riding a bus while seated in a wheelchair: A pilot study of attitudes and behavior regarding safety practices. Assist Technol. 2007;19(4):166-79. [PMID: 18335706] DOI:10.1080/10400435.2007.10131874

4. Foreman C, Hardin J. The challenges of wheelchair securement: Searching for solutions. Tampa (FL): National Center for Urban Transportation Research; 2001.

5. Nelson/Nygaard Consulting Associates. Status report on the use of wheelchairs and other mobility devices on public and private transportation. Washington (DC): Easter Seals Project ACTION; 2008.

6. Schneider LW, Manary MA, Hobson DA, Bertocci GE. Transportation safety standards for wheelchair users: A review of voluntary standards for improved safety, usability, and independence of wheelchair-seated travelers. Assist Technol. 2008;20(4):222-33. [PMID: 19160908] DOI:10.1080/10400435.2008.10131948

7. SAE J2249: Wheelchair tiedowns and occupant restraint systems. Warrendale (PA): Society of Automotive Engineers; 1999.

8. International Standards Organization. ISO/DIS 10542-2: Wheelchair tiedowns and occupant restraint systems-Part 2 Four point strap type tiedown systems. Geneva (Switzerland): ISO; 2001.

9. Shaw G. Investigation of large transit vehicle accidents and establishing appropriate protection for wheelchair riders. J Rehabil Res Dev. 2008;45(1):85-108. [PMID: 18566928] DOI:10.1682/JRRD.2007.03.0045

10. Shaw G, Gillispie T. Appropriate protection for wheelchair riders on public transit buses. J Rehabil Res Dev. 2003; 40(4):309-20. [PMID: 15074442]

DOI:10.1682/JRRD.2003.07.0309

11. Blower D, Woodrooffe J, Schneider L. Characterization of transit-bus accidents resulting in passenger injuries for use in developing alternative methods for transporting wheelchairseated travelers. Proceedings of the International Truck \& Bus Safety \& Security Symposium; 2005; Itasca, IL.

12. Wolf P, Van Roosmalen L, Bertocci G. Wheelchair tiedown and occupant restraint system issues in the real world and the virtual world: Combining qualitative and quantitative research approaches. Assist Technol. 2007;19(4):188-96.
[PMID: 18335708]

DOI:10.1080/10400435.2007.10131876

13. Project ACTION. Positioning and securing riders with disabilities and their mobility aids in transit vehicles: Designing an evaluation program. Washington (DC): Federal Transit Administration; 1995.

14. Turkovich MJ, Van Roosmalen L, Hobson DA, Porach EA. Assessment of wheelchair securement systems in a large accessible transit vehicle. Proceedings of the Rehabilitation Engineering Society of North America Conference; 2009 Jun; New Orleans, LA.

15. Wolf PJ, Van Roosmalen L, Bertocci GE. Wheelchair tiedown and occupant restraint system issues in the real world and the virtual world: Combining qualitative and quantitative research approaches. Assist Technol. 2007; 19(4):188-96. [PMID: 18335708] DOI:10.1080/10400435.2007.10131876

16. Hobson DA, Van Roosmalen L. Towards the next generation of wheelchair securement-Development of a demonstration UDIG-compatible wheelchair docking device. Assist Technol. 2007;19(4):210-22. [PMID: 18335710] DOI:10.1080/10400435.2007.10131878

17. Hunter-Zaworski K, Zaworski JR, Clarke G. The development of an independent locking securement system for mobility aids on public transportation vehicles. Vol. 2. Washington (DC): Federal Transit Administration; 1993.

18. Rutenberg U. Accommodating mobility-aids on Canadian low-floor buses using the rear-facing position design: Experience, issues and requirements. STRP 13. Toronto (Canada): Canadian Urban Transit Association; 2000.

19. Rutenberg U, Baerg R, MacNabb M, Little A, Hemily B. Assessment of low floor transit bus $\mathrm{G}$ forces on rear-facing wheelchair securement systems. Montreal (Canada): Transportation Development Centre; 2005.

20. Karg P, Buning ME, Bertocci G, Fuhrman S, Hobson D, Manary M, Schneider L, Van Roosmalen L. State of the science workshop on wheelchair transportation safety. Assist Technol. 2009;21(3):115-60. [PMID: 19908679] DOI:10.1080/10400430903175663

21. International Standards Organization. ISO 7176-19: Technical systems and aids for disabled or handicapped personsWheelchairs: Wheeled mobility devices for use in motor vehicles. Geneva (Switzerland): ISO; 2001.

22. American National Standards Institute/Rehabilitation Engineering Society of North America. ANSI/RESNA WC19: Wheelchairs used as seats in motor vehicles. Arlington (VA): ANSI/RESNA; 2001.

23. International Standards Organization. ISO 10542-3: Technical systems and aids for disabled or handicapped personsWheelchair tiedown and occupant-restraint systems-Part 3: Docking type tiedown systems. Geneva (Switzerland): ISO; 2005. 
24. International Standards Organization. ISO/DIS 10542-1: Wheelchair tiedowns and occupant restraint systems-Part 1: Requirements and test methods. Geneva (Switzerland): ISO; 2001.

25. International Standards Organization. ISO/DIS 10865-2: Assistive products for persons with disability-Wheelchair containment and occupant retention systems for motor vehicles designed for use by both sitting and standing passengers-Part 1: Systems for rearward facing wheelchairseated passengers. Geneva (Switzerland): ISO; 2011.

26. Frost K, Bertocci G. Wheelchair securement and occupant restraint practices in large accessible transit vehicles. Proceedings of the Annual Rehabilitation Engineering Society of North America Conference; 2009 Jun; New Orleans, LA.
Submitted for publication July 6, 2010. Accepted in revised form January 20, 2011.

This article and any supplementary material should be cited as follows:

Van Roosmalen L, Karg P, Hobson D, Turkovich M, Porach E. User evaluation of three wheelchair securement systems in large accessible transit vehicles. J Rehabil Res Dev. 2011;48(7):823-38.

DOI:10.1682/JRRD.2010.07.0126

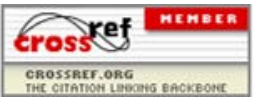

